\title{
Front Matter: Volume 8333
}

, "Front Matter: Volume 8333," Proc. SPIE 8333, Photonics and Optoelectronics Meetings (POEM) 2011: Optoelectronic Devices and Integration, 833301 (22 February 2012); doi: 10.1117/12.928084 


\title{
PROCEEDINGS OF SPIE
}

\section{Photonics and Optolectronics Meetings} (POEM) 2011

\section{Optoelectronic Devices and Integration}

\author{
Erich Kasper \\ Jinzhong Yu \\ Xun Li \\ Xinliang Zhang \\ Jinsong Xia \\ Junhao Chu \\ Zhijiang Dong \\ Bin Hu \\ Yan Shen \\ Editors
}

\section{2-5 November 2011 \\ Wuhan, China}

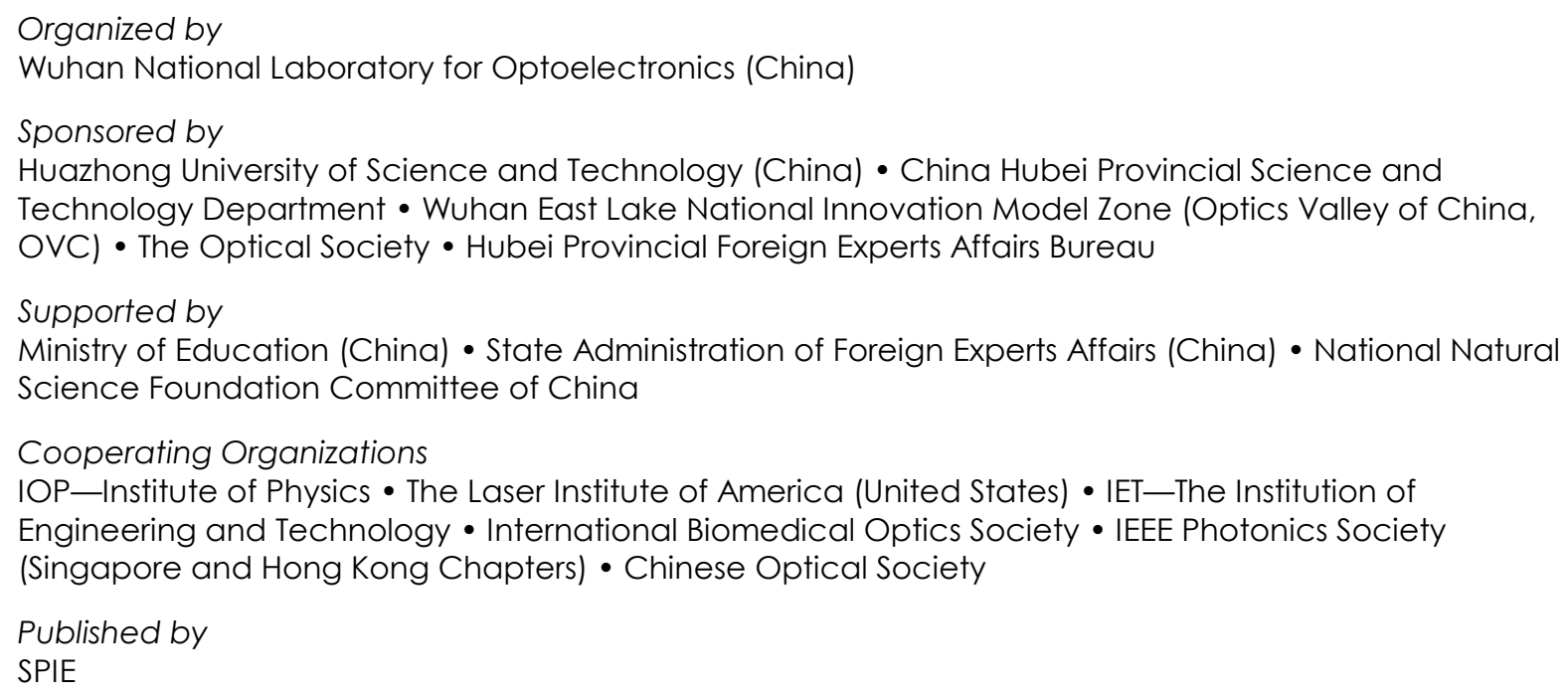

Volume 8333 
The papers included in this volume were part of the technical conference cited on the cover and title page. Papers were selected and subject to review by the editors and conference program committee. Some conference presentations may not be available for publication. The papers published in these proceedings reflect the work and thoughts of the authors and are published herein as submitted. The publisher is not responsible for the validity of the information or for any outcomes resulting from reliance thereon.

Please use the following format to cite material from this book:

Author(s), "Title of Paper," in Photonics and Optolectronics Meetings (POEM) 2011 : Optoelectronic Devices and Integration, edited by Erich Kasper, Jinzhong Yu, Xun Li, Xinliang Zhang, Jinsong Xia, Junhao Chu, Zhijiang Dong, Bin Hu, Yan Shen, Proceedings of SPIE Vol. 8333 (SPIE, Bellingham, WA, 2012) Article CID Number.

ISSN 0277-786X

ISBN 9780819489906

Published by

SPIE

P.O. Box 10, Bellingham, Washington 98227-0010 USA

Telephone +1 3606763290 (Pacific Time) · Fax +1 3606471445

SPIE.org

Copyright ( 2012, Society of Photo-Optical Instrumentation Engineers

Copying of material in this book for internal or personal use, or for the internal or personal use of specific clients, beyond the fair use provisions granted by the U.S. Copyright Law is authorized by SPIE subject to payment of copying fees. The Transactional Reporting Service base fee for this volume is $\$ 18.00$ per article (or portion thereof), which should be paid directly to the Copyright Clearance Center (CCC), 222 Rosewood Drive, Danvers, MA 01923. Payment may also be made electronically through CCC Online at copyright.com. Other copying for republication, resale, advertising or promotion, or any form of systematic or multiple reproduction of any material in this book is prohibited except with permission in writing from the publisher. The CCC fee code is 0277-786X/12/\$18.00.

Printed in the United States of America.

Publication of record for individual papers is online in the SPIE Digital Library.

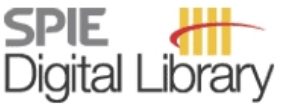

SPIEDigitalLibrary.org

Paper Numbering: Proceedings of SPIE follow an e-First publication model, with papers published first online and then in print and on CD-ROM. Papers are published as they are submitted and meet publication criteria. A unique, consistent, permanent citation identifier (CID) number is assigned to each article at the time of the first publication. Utilization of CIDs allows articles to be fully citable as soon as they are published online, and connects the same identifier to all online, print, and electronic versions of the publication. SPIE uses a six-digit CID article numbering system in which:

- The first four digits correspond to the SPIE volume number.

- The last two digits indicate publication order within the volume using a Base 36 numbering system employing both numerals and letters. These two-number sets start with 00, 01, 02, 03, 04, $05,06,07,08,09,0 A, 0 B \ldots$. OZ, followed by 10-1Z, 20-2Z, etc.

The CID number appears on each page of the manuscript. The complete citation is used on the first page, and an abbreviated version on subsequent pages. Numbers in the index correspond to the last two digits of the six-digit CID number. 


\title{
Contents
}

\author{
ix Symposium Committees \\ xi Conference Committee \\ xiii Introduction
}

\section{PART A Optoelectronic Devices and Integration (OEDI)}

OPTOELECTRONIC DEVICES AND SUBSYSTEM FOR OPTICAL NETWORKS

833302 Novel optical en/decoder based on micro-ring-reflector (Invited Paper) [8333-62]

X. Wang, Z. Gao, Heriot-Watt Univ. (United Kingdom)

\section{SLOW AND FAST LIGHT DEVICES}

833303 Continuously tunable time delay and advance in coupling-modulated microring resonators [8333-58]

Y. Hu, X. Xiao, X. Li, K. Xiong, Z. Li, Y. Li, T. Chu, Y. YU, J. Yu, Institute of Semiconductors (China)

\section{SILICON PHOTONICS AND OPTICAL INTERCONNECTION}

833304 Integrated switchable ring filters on silicon for optical interconnects (Invited Paper) [8333-48] J. Yang, T. Hu, C. Qiu, X. Jiang, W. Wang, P. Liu, Zhejiang Univ. (China); M. Yang, Univ. of Nevada (United States) and Zhejiang Univ. (China)

833305 CMOS compatible silicon-based Mach-Zehnder optical modulators with improved extinction ratio [8333-31]

Z. Li, L. Zhou, Y. Hu, X. Xiao, Y. Yu, J. Yu, Institute of Semiconductors (China)

\section{MICROWAVE PHOTONICS AND FREE SPACE OPTICAL COMMUNICATION}

833306 Photonic generation of ultra-wideband pulses using a fiber delay interferometer [8333-23] F. Wang, Chongqing Univ. of Technology (China); X. Zhang, Y. Zhang, Huazhong Univ. of Science and Technology (China); E. XU, Nanjing Univ. of Posts and Telecommunications (China)

$833307 \quad$ 7.5Gbps 40 km horizontal path DWDM optical link experiment [8333-35]

Y. Ai, Z. Xiong, J. Chen, Wuhan Univ. (China); F. Zhang, Y. Liu, The Institute of Beijing Tracking and Communication Technology (China); S. Zhang, Beijing Guokehuanyu Space Technology Inc. (China); X. Shan, D. Ran, Y. Xiao, Wuhan Univ. (China) 
833308 Dispersion management in a passively mode-locked VECSEL at $1.55 \mu \mathrm{m}$ [8333-40] Z. Zhao, S. Bouchoule, Lab. de Photonique et de Nanostructures, CNRS (France); J. Decobert, Alcatel III-V Lab (France); E. Galopin, J.-C. Harmand, J.-L. Oudar, Lab. de Photonique et de Nanostructures, CNRS (France)

$833309 \quad$ All-optical signal processing using planar Bragg gratings [8333-43] C. Sima, J. C. Gates, H. L. Rogers, B. D. Snow, C. Holmes, M. N. Zervas, P. G. R. Smith, Univ. of Southampton (United Kingdom)

8333 OA Single-mode silicon-on-insulator elliptical microdisk resonators with high $Q$ factors [8333-60] K. Xiong, X. Xiao, Y. Hu, Z. Li, T. Chu, Y. Yu, J. YU, Institute of Semiconductors (China)

$8333 \mathrm{OB} \quad$ Analysis of modulation characteristics of widely tunable sampled-grating distributed reflector (SGDBR) lasers based on transmission line laser model [8333-46]

W. Chen, S. Hu, Y. Yu, Wuhan National Lab. for Optoelectronics (China)

8333 OC Miniature intensity modulator based on a silicon-polymer hybrid plasmonic waveguide [8333-12]

X. Sun, L. Zhou, X. Li, Z. Hong, S. Liu, J. Chen, Shanghai Jiao Tong Univ. (China)

8333 OD Systematic investigation of coupling-modulated microring resonators based on interleaved p-n junctions [8333-59]

X. Li, Y. Hu, X. Xiao, K. Xiong, Z. Li, Y. Li, T. Chu, Y. YU, J. Yu, Institute of Semiconductors (China)

$8333 \mathrm{OE}$ The analysis of optical transmission in three-dimensional waveguide coupler [8333-44] T. Lin, Q. Miao, Wuhan Univ. (China); J. He, Huazhong Univ. of Science and Technology (China); C. Li, P. He, Wuhan Univ. (China)

8333 OF Tunable pulse compression via doublet Brillouin gain lines in an optical fiber [8333-49] Q. Tian, G. Qin, L. Liu, T. Jiang, W. Qin, Jilin Univ. (China)

\section{SILILCON PHOTONICS AND OTHER RELATED TECHNOLOGIES}

8333 OG Bioinspired solar water splitting, sensitized solar cells, and ultraviolet sensor based on semiconductor nanocrystal antenna/graphene nanoassemblies [8333-10]

H. Chang, Tohoku Univ. (Japan); X. Lv, Technical Institute of Physics and Chemistry (China);

Z. Zheng, The Hong Kong Polytechnic Univ. (Hong Kong, China); H. Wu, Tohoku Univ. (Japan)

$8333 \mathrm{OH} \quad$ Nanomedicine crystals-inspired optoelectronic device materials and processing [8333-53] Y. Fang, F. Wang, R. Wu, Fudan Univ. (China)

8333 Ol 25Gbit/s fully CMOS-compatible silicon modulator based on interleaved PN junctions [8333-56]

X. Xiao, Y. Hu, H. XU, X. Li, K. Xiong, Z. Li, T. Chu, Y. YU, J. Yu, Institute of Semiconductors (China) 
8333 0J The effects of oxide apertures on the characteristics of resonant-cavity light-emitting diodes [8333-13]

W. Yang, J. Li, P. Sun, L. Ma, Beijing Univ. of Technology (China)

8333 OK Theoretical and simulation analysis of the fiber optical parametric amplifier (FOPA) with cascaded structure [8333-37]

J. Gao, Y. Cao, F. Chen, B. Sun, Z. Hu, Univ. of Electronic Science and Technology of China (China)

8333 OL Polarization-controlled single-mode photonic-crystal VCSEL [8333-20]

T. Cao, C. Xu, S. Wei, Y. Xie, M. Mao, Beijing Univ. of Technology (China)

8333 OM The fabrication and performance analysis of proton implantation VCSEL [8333-11]

M. Mao, C. Xu, S. Wei, Y. Xie, T. Cao, Beijing Univ. of Technology (China)

8333 ON Full 3D FDTD analysis of transverse mode characteristics in surface relief VCSELs [8333-08]

S. Wei, C. Xu, M. Mao, Y. Xie, T. Cao, Beijing Univ. of Technology (China)

833300 Simulation study on spectrum beam combining based on reflection volume Bragg grating [8333-18]

Y. Yi, M. Li, C. Hu, F. Chen, Wuhan Univ. of Technology (China)

$8333 \mathrm{OP}$ Synthesis and fluorescence switching of a photochromic diarylethene bearing pyridine unit [8333-26]

M. Liu, G. Liu, S. Cui, Jiangxi Science and Technology Normal Univ. (China)

$83330 Q \quad$ Synthesis and properties of a novel diarylethene compound based on five and six rings [8333-61]

Z. Tong, S. Pu, S. Cui, Jiangxi Science \& Technology Normal Univ. (China)

8333 OR Synthesis of a symmetrical diarylethene with two different substituents for optical recording [8333-25]

S. Cui, S. Pu, W. Liu, Jiangxi Science and Technology Normal Univ. (China)

8333 OS A distributed big data storage and data mining framework for solar-generated electricity quantity forecasting [8333-45]

J. Wang, Huazhong Univ. of Science and Technology (China) and Wuhan National Lab. for Optoelectronics, (China); Y. Chen, R. Hua, Huazhong Univ. of Science and Technology (China); P. Wang, Huazhong Univ. of Science and Technology (China) and Wuhan National Lab. for Optoelectronics, (China); J. Fu, Meteorological Service Ctr. of Hubei Province (China)

8333 OT Dispersion engineering of slot photonic crystal waveguides [8333-22]

C. Caer, E. Cassan, Institut d'Electronique Fondamentale, Univ. Paris-Sud XI (France)

8333 OU Study on unidirectional acquisition in free-space optical communication based on GPS [8333-17]

Y. Xiao, Wuhan Univ. (China) and Xiaogan Univ. (China); Y. Ai, R. Dong, Wuhan Univ. (China) 
$8333 \mathrm{OV}$ Experiment of space laser communication based on adaptive optics system [8333-32] Z. Xiong, Y. Ai, J. Chen, Wuhan Univ. (China); E. Chen, Beijing Institute of Tracking and Communication Technology (China); Y. Wu, The Institute of Optoelectronics (China)

8333 oW Catadioptric dual-zone Fresnel condenser with super relative aperture [8333-16] J. Wang, E. QU, H. Yang, J. Cao, Z. Fan, Xi'an Institute of Optics and Precision Mechanics (China)

8333 0X A butt-coupled low dispersion slow light photonic crystal waveguide [8333-06] X. Zhang, H. Peng, X. Fan, D. Chen, Z. Wu, Univ. of Electronic Science and Technology of China (China)

8333 OY All-optical in-band OSNR monitors based on unphase-matched four-wave mixing [8333-30] S. Sun, J. Li, S. Cui, C. Xiang, L. Li, Q. You, D. Liu, Huazhong Univ. of Science and Technology (China) and Wuhan National Lab. for Optoelectronics (China)

$83330 Z$ Optically switchable and tunable ultrawideband doublet generation using semiconductor optical amplifier and optical delay line [8333-41]

Z. Hu, B. Sun, F. Chen, K. Chen, Y. Cao, Univ. of Electronic Science and Technology of China (China)

833310 Investigation on nonlinear characteristics of the Mach-Zehnder intensity modulator based on Bessel series expansion [8333-02]

X. Fan, J. Yan, X. Zhang, L. XU, L. Chen, S. Zhang, Y. Liu, Univ. of Electronic Science and Technology of China (China)

833311 Diffraction properties study of multi-layer reflection volume holographic grating under ultra-short pulse readout [8333-19]

Y. Yi, M. Li, F. Chen, L. Wang, Wuhan Univ. of Technology (China)

$833312200 \mathrm{GHz}-s p a c i n g$ WDM transmission system employing ultrawideband optical signals [8333-39]

J. Shao, J. Sun, Wuhan National Lab. for Optoelectronics (China) and Huazhong Univ. of Science and Technology (China)

833313 Optimizing the phase-matching parameters of a BIBO crystal for ultrafast spontaneous parametric down conversion [8333-34]

G.-W. Huo, T.-Y. Zhang, R.-G. Wan, Xi'an Institute of Optics and Precision Mechanics (China); M.-Z. Zhang, Xi'an Univ. Post and Telecommunication (China); G.-H. Cheng, W. Zhao, Xi'an Institute of Optics and Precision Mechanics (China)

833314 Experiments on a compact and robust polarization-entangled photon source [8333-29] S.-W. Zhang, Xi'an Institute of Optics and Precision Mechanics (China) and Xi'an Jiaotong Univ. (China) and Graduate School of Chinese Academy of Sciences (China); T.-Y. Zhang, Xi'an Institute of Optics and Precision Mechanics (China); Y.-P. Yao, Xi'an Institute of Optics and Precision Mechanics (China) and Graduate School of Chinese Academy of Sciences (China); R.-G. Wan, Xi'an Institute of Optics and Precision Mechanics (China); S.-W. Zou, Xi'an Institute of Optics and Precision Mechanics (China) and Graduate School of Chinese Academy of Sciences (China) 
833315 A study of thermal properties of power AIGalnP and InGaN LEDs [8333-09]

Y. Ding, W. Guo, B. Cui, D. Cui, G. Wu, W. Yan, Beijing Univ. of Technology (China)

833316 Influence of the waveguide coupling fluctuation on the light coupling dynamics [8333-50] L. Ju, W. Wang, Hubei Univ. (China); Y. Wang, Liteon Singapore Pte Ltd. (Singapore)

833317 All optical Schmitt trigger based on nonlinear quasi periodic photonic crystals [8333-15] M. H. Teimourpour, Kermanshah Univ. of Technology (Iran, Islamic Republic of)

PART B Solar Cells, Solid State Lighting, and Information Display Technologies (SSID)

WORKSHOP ON FRONTIER SCIENCE OF RENEWABLE ENERGY IN ORGANIC OPTOELECTRONICS

833318 Organic magnetic-field effect examined in frequency domain and time domain (Keynote Paper) [8333-113]

F. Wang, R. Lin, K. A. Hutchinson, J. Rybicki, M. Wohlgenannt, Univ. of lowa (United States)

833319 Effect of temperature and magnetic field on the photocurrent response of biomolecular bulk-hetero junction (Invited Paper) [8333-1 14]

H. Tajima, Y. Sekiguchi, The Univ. of Tokyo (Japan); M. Matsuda, Kumamoto Univ. (Japan)

$83331 \mathrm{~A}$ Spin-orbit coupling, spin relaxation, and spin diffusion in organic solids (Invited Paper) [8333-116]

Z.-G. YU, SRI International (United States)

8333 1B Exciton formation in dye doped OLEDs using electrically detected magnetic resonance (Keynote Paper) [8333-111]

A. Batagin-Neto, UNESP (Brazil); J. A. Gómez, FFCLRP-USP (Brazil); F. A. Castro, National Physical Lab. (United Kingdom); F. Nüesch, EMPA (Switzerland); L. Zuppiroli, Lab.

d'optoélectronique dês matériaux moléculaire, (Switzerland); C. F. O. Graeff, UNESP (Brazil)

PROPERTIES OF OPTOELECTRONIC SEMICONDUCTOR MATERIALS

8333 1C Light concentration in polymer bulk heterojunction solar cells with plasmonic nanoparticles [8333-101]

J. Zhu, B. Zeng, Univ. of Electronic Science and Technology of China (China); R. S. Kim, Air Force Research Lab. (United States); Z. Wu, Univ. of Electronic Science and Technology of China (China)

\section{POSTER SESSION}

8333 1D Optical properties of $\mathrm{TiO}_{2}$ thin film grown on quartz substrate by sol-gel method [8333-105] J. Tian, East China Normal Univ. (China); H. Deng, Shanghai Univ. (China); L. Sun, H. Kong, P. Yang, J. Chu, East China Normal Univ. (China) 
$8333 \mathrm{lE}$ Optical property of the co-doped La and $\mathrm{Mg} \mathrm{BiFeO}_{3}$ films fabricated by sol-gel method [8333-104]

L. Peng, East China Normal Univ. (China); H. Deng, Shanghai Univ. (China); J. Tian, H. Deng, P. Yang, J. Chu, East China Normal Univ. (China)

$8333 \mathrm{IF}$ Structural and optical properties of $\mathrm{LuFeO}_{3}$ thin films prepared on silicon (100) substrate by pulsed laser deposition [8333-102]

L. Zhu, East China Normal Univ. (China); H. Deng, Shanghai Univ. (China); J. Tian, P. Yang,

J. Chu, East China Normal Univ. (China)

8333 IG Si nanowires arrays fabricated by wet chemical etching for antireflection and self-cleaning [8333-112]

W. Zhang, Wuhan National Lab. for Optoelectronics (China) and Wuhan Univ. of Science \& Technology (China); X. Wang, W. Lai, Z. Tang, Wuhan National Lab. for Optoelectronics (China)

$8333 \mathrm{1H}$ The effects of growth temperature of the pulse atomic layer epitaxy AIN films grown on sapphire by MOCVD [8333-117]

S. L. Li, H. Wang, J. Zhang, Y.-Y. Fang, W. Fan, W. Tian, Y. Li, Y. Tian, H. Xiong, C. Q. Chen, Wuhan National Lab. for Optoelectronics (China)

833311 The influence of AIN buffer layer thickness grown by pulsed atomic layer epitaxy on the properties of GaN epilayer [8333-118]

J. Zhang, H. Xiong, S. L. Li, H. Wang, Y. Y. Fang, J. Y. Tang, Y. Li, W. Tian, C. Q. Chen, Wuhan National Lab. for Optoelectronics (China)

Author Index 


\title{
Symposium Committees
}

\author{
Symposium Chairs
}

Chaohui Ye, Wuhan National Laboratory for Optoelectronics (China)

Zhong Lin Wang, Georgia Institute of Technology (United States) and Wuhan National Laboratory for Optoelectronics (China)

Bingkun Zhou, Tsinghua University (China)

International Advisory Committee

Stephen Z. D. Cheng, University of Akron (United States)

Yibing Cheng, Monash University (Australia) and Wuhan National Laboratory for Optoelectronics (China)

Min Gu, Swinburne University of Technology (Australia)

Andrew B. Holmes, The University of Melbourne (Australia)

Chinlon Lin, Bell Laboratories (retired, United States)

Shenggang Liu, University of Electronic Science and Technology of China (China)

Jesper Moerk, Technical University of Denmark (Denmark)

Dennis L. Matthews, University of California, Davis (United States)

Jiacong Shen, Jilin University (China)

Chester C. T. Shu, Chinese University of Hong Kong (Hong Kong, China)

Valery V. Tuchin, Saratov State University (Russian Federation)

Bruce Tromberg, University of California, Irvine (United States)

Peiheng Wu, University of Nanjing (China)

Alan Willner, University of Southern California (United States)

Lihong Wang, Washington University in St. Louis (United States)

C. P. Wong, Georgia Institute of Technology (United States)

Jianquan Yao, Tianjin University (China) and Wuhan National Laboratory for Optoelectronics (China)

Xi Zhang, Tsinghua University (China)

$X$. C. Zhang, Rensselaer Polytechnic Institute (United States) and Wuhan National Laboratory for Optoelectronics (China)

Program Committee

Qingming Luo, Chair, Wuhan National Laboratory for Optoelectronics (China)

Perry Ping Shum, Nanyang Technological University (Singapore) and Wuhan National Laboratory for Optoelectronics (China)

Yibing Cheng, Monash University (Australia) and Wuhan National Laboratory for Optoelectronics (China)

Junhao Chu, Shanghai Institute of Technical Physics (China)

Zhijiang Dong, Aqualite Co., Ltd. (China)

Pierre Galarneau, National Optics Institute, INO (Canada) 
Bin Hu, University of Tennessee (United States) and Wuhan National Laboratory for Optoelectronics (China)

Erich Kasper, Universität Stuttgart (Germany)

Xun Li, McMaster University (Canada) and Wuhan National Laboratory for Optoelectronics (China)

Xu Liu, Zhejiang University (China)

Richard Penty, University of Cambridge (United Kingdom)

Chester Shu, Chinese University of Hong Kong (Hong Kong, China)

Valery V. Tuchin, Saratov State University (Russian Federation)

Lihong Wang, Washington University in St. Louis (United States)

Dapeng Yan, Raycus Fiber Laser Technologies Company Ltd. (China)

Jianquan Yao, Tianjin University (China) and Wuhan National Laboratory for Optoelectronics (China)

Jinzhong Yu, Institute of Semiconductors (China)

X. C. Zhang, Rensselaer Polytechnic Institute (United States) and Wuhan National Laboratory for Optoelectronics (China)

Zisen Zhao, Fiberhome (China), Wuhan Research Institute of Post and Telecommunications (China), and Wuhan National Laboratory for Optoelectronics (China)

Local Organizing Committee

Lin Lin, Chair, Wuhan National Laboratory for Optoelectronics (China)

Xiwen Sun, Administration Committee of Wuhan East Lake Hi-Tech Development Zone (China)

Sihai Chen, Wuhan National Laboratory for Optoelectronics (China) Tao Jiang, Huazhong University of Science and Technology (China)

Pengcheng Li, Wuhan National Laboratory for Optoelectronics (China) Jinsong Liu, Huazhong University of Science and Technology (China) Yan Shen, Huazhong University of Science and Technology (China) Wen Sun, Chutian Laser Group (China)

Jinsong Xia, Wuhan National Laboratory for Optoelectronics (China) Changsheng Xie, Wuhan National Laboratory for Optoelectronics (China)

Xinliang Zhang, Wuhan National Laboratory for Optoelectronics (China)

Zhihong Zhang, Wuhan National Laboratory for Optoelectronics (China)

Yuandi Zhao, Wuhan National Laboratory for Optoelectronics (China) Xiao Zhu, Huazhong University of Science and Technology (China)

Local Secretariat

Xiaochun Xiao, Wuhan National Laboratory for Optoelectronics (China)

Weiwei Dong, Wuhan National Laboratory for Optoelectronics (China) 


\title{
Conference Committee
}

\section{Part A Optoelectronic Devices and Integration (OEDI)}

\author{
Conference Chairs
}

Erich Kasper, Universität Stuttgart (Germany)

Jinzhong Yu, Institute of Semiconductors (China)

Xun Li, McMaster University (Canada)

Xinliang Zhang, Wuhan National Laboratory for Optoelectronics (China)

Jinsong Xia, Wuhan National Laboratory for Optoelectronics (China)

\section{Session Chairs}

Optical Integration

Xun Li, McMaster University (Canada)

Surface Plasma and Plasmonics

Jinsong Xia, Wuhan National Laboratory for Optoelectronics (China)

Optoelectronic Devices and Subsystem for Optical Networks

Liming Zhang, Alcatel-Lucent Bell Laboratories (United States)

Devices Mechanisms and Physics

Yongzhen Huang, Institute of Semiconductors (China)

Slow and Fast Light Devices

Xuehua Wang, Sun Yat-Sen University (China)

Silicon Photonics and Optical Interconnection

Jinzhong Yu, Institute of Semiconductors (China)

Optical Fiber Devices and Applications

Dongning Wang, The Hong Kong Polytechnic University (Hong Kong, China)

Microwave Photonics and Free Space Optical Communication Junqiang Sun, Wuhan National Laboratory for Optoelectronics (China)

Novel Technologies for Optical Network

Christophe Peucheret, Technical University of Denmark (Denmark) 
Best Student Paper Competition

Xinliang Zhang, Wuhan National Laboratory for Optoelectronics

(China)

Semiconductor Lighting

Erich Kasper, Universität Stuttgart (Germany)

Novel Mechanisms and Materials

Eric Cassan, Institut d'Électronique Fondamentale (France)

Key Devices for Optical Networks

Yonglin Yu, Wuhan National Laboratory for Optoelectronics (China)

Sililcon Photonics and Other Related Technologies

Yi Wang, Wuhan National Laboratory for Optoelectronics (China)

Poster Session

Xinliang Zhang, Wuhan National Laboratory for Optoelectronics (China)

\section{Part B Solar Cells, Solid State Lighting, and Information Display Technologies (SSID)}

Conference Chairs

Junhao Chu, Shanghai Institute of Technical Physics (China)

Zhijiang Dong, Aqualite Co., Ltd. (China)

Bin Hu, The University of Tennessee (United States) and Wuhan National Laboratory for Optoelectronics (China)

Yan Shen, Huazhong University of Science and Technology (China)

\section{Session Chairs}

Workshop on Frontier Science of Renewable Energy in Organic

Optoelectronics

Kunio Awaga, Nagoya University (Japan)

Carlo Taliani, Institute for Nanostructured Materials (Italy)

Markus Wohlgenannt, The University of lowa (United States)

Peter A. Bobbert, Technische Universiteit Eindhoven (Netherlands)

Thin Films Solar Cells

Yuguang Ma, Jilin University (China)

Best Student Paper Competition

Lixiang Wang, Changchun Institute of Applied Chemistry (China) 
Novel Optoelectronic Devices and Processing Techniques

Yongfang Li, Institute of Chemistry (China)

Junbiao Peng, South China University of Technology (China)

Properties of Optoelectronic Semiconductor Materials

J. C. A. Huang, National Cheng Kung University (Taiwan)

He Tian, East China University of Science and Technology (China)

Poster Session

Lixiang Wang, Changchun Institute of Applied Chemistry (China) 
Downloaded From: https://www.spiedigitallibrary.org/conference-proceedings-of-spie on 26 Apr 2023

Terms of Use: https://www.spiedigitallibrary.org/terms-of-use 


\section{Introduction}

The 4th International Photonics and Optoelectronics Meetings (POEM 2011) combined with the 10th International Conference on Photonics and Imaging in Biology and Medicine (PIBM 2011) was held during 2-5 November 2011 at Wuhan Science \& Technology Convention \& Exhibition Center, Wuhan, P.R. China. This volume contains manuscripts of a selection from the invited talks delivered at the conference and the poster presentations.

The POEM is an international conference of broad scale and multidiscipline, which is extended over a large area of optoelectronics, initiated by WNLO. Aimed at giving full play to the industrial advantage of Wuhan Optics Valley of China, building an independent brand for our international conference, facilitating the regional economic development, promoting the academic reputation and international status of WNL), domestic and internationally renowned academic institutes and organizations in the area of optoelectronics were invited to provide professional support. On such an international platform, POEM was built into a high-level academic conference that integrates academia and industry with the support from Wuhan Optics Valley of China.

POEM 2011 broadened the themes, conducting extensive discussions on four major areas including biomedical photonics, industrial photonics, information photonics and photonics for energy.

POEM 2011 was open to all individuals and entities, domestic and international, which have interest in our four technical areas. The six sub conferences of POEM 2011 were: (1) 10th International Conference on Photonics and Imaging in Biology and Medicine (PIBM 2011); (2) Laser and Tera-Hertz Science and Technology (LTST); (3) Optoelectronic Sensing and Imaging (OSI); (4) Optoelectronic Devices and Integration (OEDI); (5) Optical Communication Systems and Networking (OCSN); and (6) Solar Cells, Solid State Lighting and Information Display Technologies (SSID).

Besides the six sub conferences in four major areas, POEM was organized along with symposiums and workshops including: Workshop on Technology Transfer Models, Sino-Russia Symposium on Biophotonics and Biomedical Photonic, the China-Australia Symposium on Optoelectronic Materials and Devices, 1st Workshop on International Laser Technology and Industrialization, 5th Sino-Russian Laser Technology Forum, 2nd International Workshop on Nanomaterials and Nanosystems (INN 2011). The 40th anniversary of the College of Optoelectronic Science and Engineering at HUST was also celebrated at the same time. Activities such as the Workshop on Immunophotonics, the Workshop on Optical Imaging in Brain Connectivity, the Workshop on Organic Spin Optoelectronics, as well as training courses in Optoelectronic Devices and Integration, and courses given by 
travelogue scholars from OSA were arranged to provide a variety of choices for the attendees.

POEM owes its distinguished features to its wide-ranging topics and contents, highly professional delegates, and a strong academic atmosphere. Presentations given by experts worldwide demonstrated previously unpublished cutting-edge scientific achievements. Popular activities such as speeches and posters were intensively organized to provide a unique and immediate access for scientists, entrepreneurs, and students all over the world.

We gratefully thank the financial support by 111 Project (B07038), the National Natural Science Foundation Committee of China (NNSFC)'s funding support. We would like to thank all the authors for their contributions to POEM 2011 and all the members of the committees for their cooperation and time spent reviewing submissions. We would like to extend our sincere thanks for your attendance, support, and contributions at POEM 2011 in Wuhan.

According to different technical areas, the proceedings were divided into six topical volumes:

- 10th International Conference on Photonics and Imaging in Biology and Medicine (PIBM 2011),

- Laser and Tera-Hertz Science and Technology (LTST),

- Optoelectronic Sensing and Imaging (OSI),

- Optoelectronic Devices and Integration (OEDI),

- Optical Communication Systems and Networking (OCSN), and

- Solar Cells, Solid State Lighting and Information Display Technologies (SSID).

\section{Chaohui Ye \\ Zhong lin Wang \\ Bingkun Zhou}

